Check for updates

Cite this: Mater. Adv., 2021, 2, 2104

Received 17th January 2021, Accepted 15th February 2021

DOI: $10.1039 / \mathrm{d} 1 \mathrm{ma} 00038 \mathrm{a}$

rsc.li/materials-advances

\title{
A synergetic effect between photogenerated carriers and photothermally enhanced electrochemical urea-assisted hydrogen generation on the $\mathrm{Ni}-\mathrm{NiO} / \mathrm{Nickel}$ Foam catalyst $\dagger$
}

\author{
Qi Wang, ${ }^{a}$ Xing Cheng, (D) ${ }^{a}$ Yukun Sun, ${ }^{\mathrm{b}}$ Zaicheng Sun, (D) ${ }^{\mathrm{b}}$ Dong Wang, (D) *c \\ Ge Chen (D) *a and Peter Schaaf (D) ${ }^{c}$
}

\begin{abstract}
The urea-assisted water electrolysis reactions are of great significance for solving the increasingly serious energy crisis and environmental pollution. Recently, the photo-driven effect strategy has been demonstrated to be an efficient external driving force for improving electrocatalytic activities. Herein, we synthesized $\mathrm{Ni}-\mathrm{NiO}$ heterostructured nanosheet arrays grown on $\mathrm{Ni}$ foam (denoted as $\mathrm{Ni}-\mathrm{NiO} / \mathrm{NF}$ ) as a bifunctional electrocatalyst enhancing the urea oxidation reaction (UOR) and hydrogen evolution reaction (HER) activities simultaneously under light irradiation. Moreover, when the catalyst is used in a two-electrode system for the urea-assisted water electrolysis reaction, the cell potential could be reduced to $1.48 \mathrm{~V}$ to achieve the current density of $10 \mathrm{~mA} \mathrm{~cm}{ }^{-2}$ after exposure to light irradiation, as well as remarkable stability. Our studies demonstrate that the enhancement of the HER \& UOR activities is attributed to a synergetic effect between photogenerated carriers and photothermy.
\end{abstract}

\section{Introduction}

Hydrogen has been considered as a potential green fuel to replace conventional fossil fuels in the future owing to its abundance and zero emissions. ${ }^{1,2}$ Hydrogen production by electrolytic water splitting is a simple and eco-friendly method. ${ }^{3}$ However, due to the sluggish kinetics of the anodic oxygen evolution reaction (OER), a considerable overpotential is usually required. ${ }^{4-6}$ The overpotential is hopeful to be reduced by replacing the OER with a more efficient oxidation process, such as methanol oxidation reaction, ${ }^{7}$ ethanol oxidation reaction, ${ }^{8}$ selective semi-dehydrogenation of tetrahydroisoquinolines, ${ }^{9}$ electrochemical synthesis of nitric acid ${ }^{10}$ and the urea oxidation reaction (UOR). ${ }^{11-13}$ Among these alternative methods, the urea oxidation reaction has been found to be a more efficient and energy-saving alternative

\footnotetext{
${ }^{a}$ Beijing Key Laboratory for Green Catalysis Separation, Department of environmental and Chemical Engineering, Faculty of Environmental and life science, Beijing University of Technology, No. 100, Ping Le Yuan, Chaoyang District, Beijing 100124, P. R. China. E-mail: chenge@bjut.edu.cn

${ }^{b}$ Beijing Key Lab for Green Catalysis and Separation, Department of Chemistry and Biology, Beijing University of Technology, Beijing 100124, China

${ }^{c}$ Chair Materials for Electrical Engineering and Electronics, Institute of Materials Science and Engineering, Institute of Micro and Nanotechnology MacroNano ${ }^{\circledR}, T U$ Ilmenau, Gustav-Kirchhoff-Str. 5, 98693, Ilmenau, Germany.

E-mail: dong.wang@tu-ilmenau.de

$\dagger$ Electronic supplementary information (ESI) available: More XRD, SEM, IR images, and electrochemical measurement of the samples. See DOI: 10.1039/ d1ma00038a
}

half-reaction with a very low thermodynamic potential of $0.37 \mathrm{~V} \cdot{ }^{14,15}$ Thus, urea-assisted water electrolysis, combining the HER and the UOR, can significantly reduce energy consumption. ${ }^{16-18}$ However, the urea oxidation reaction is a very complex reaction involving a $6 \mathrm{e}^{-}$transfer process in the process of gas release $\left(\mathrm{CO}\left(\mathrm{NH}_{2}\right)_{2}+6 \mathrm{OH}^{-} \rightarrow \mathrm{N}_{2}+\mathrm{CO}_{2}+5 \mathrm{H}_{2} \mathrm{O}+6 \mathrm{e}^{-}\right.$, UOR $) \cdot{ }^{19,20}$ Therefore, it is highly desirable to develop a new strategy to improve the reaction rate.

In recent years, light irradiation was introduced into an electrochemical system because it can efficiently improve the electrocatalytic performance. The mechanism might be the generation of hot carriers as well as the photothermal effect via excitation of surface plasmon resonance (SPR) effect on noble metal nanomaterials. ${ }^{21,22}$ For example, the plasmonic gold nanostar (AuNSs) can accelerate the electrocatalytic oxidation of ascorbic acid AA via LSPR excitation. ${ }^{23}$ In addition to noble metals, some semiconducting metal oxides exhibit excellent water splitting performance through a photogenerated-carrierdriven strategy. ${ }^{24}$ On the other hand, the solar energy can be absorbed and converted into thermal energy to increase the temperature of the catalysts and improve the sluggish kinetics, thus enhancing the electrocatalytic activity. ${ }^{25,26}$ For instance, the operating temperature of the $\mathrm{Co}_{3} \mathrm{O}_{4}$ electrode is elevated in situ under near-infrared (NIR) light irradiation, resulting in enhanced OER activity due to its accelerated electrical conductivity, reaction kinetics, and desorption rate of $\mathrm{O}_{2}$ bubbles from the electrode. ${ }^{27}$ It is a promising strategy for increasing the 
conversion efficiency from electrical energy to chemical energy through the utilization of sustainable solar energy. ${ }^{28}$ Thus, the utilization of photo-driven urea-assisted hydrogen generation is an interesting route and has not been reported yet.

Herein, Ni-NiO heterostructured nanosheet arrays grown on $\mathrm{Ni}$ foam (denoted as Ni-NiO/NF) are designed as a bifunctional electrocatalyst for both the UOR and HER. And we have innovatively applied the photo-driven effect on urea electrolysis. Under the illumination of light, the Ni-NiO/NF electrode yields a current density of $10 \mathrm{~mA} \mathrm{~cm}^{-2}$ at potentials of $1.34 \mathrm{~V}$ and $119 \mathrm{mV}$ for the UOR and HER, respectively, lower than that without light illumination. Moreover, when the catalyst was used in a twoelectrode system for the urea-assisted water electrolysis reaction, the cell potential could be reduced to $1.48 \mathrm{~V}$ to achieve the current density of $10 \mathrm{~mA} \mathrm{~cm}{ }^{-2}$ after exposure to light irradiation. Our studies demonstrate that the enhancement of the HER \& UOR activities is attributed to a synergetic effect between photogenerated carriers and photothermy.

\section{Experimental}

\section{Materials}

$\mathrm{Ni}\left(\mathrm{NO}_{3}\right)_{2} \cdot 6 \mathrm{H}_{2} \mathrm{O}$ (nickel nitrate hexahydrate, $99 \%$, Tianjin Fuchen Chemical Reagents Co.), HMT (hexamethylenetetramine, $\geq 99 \%$, Beijing Chemical Corporation), $\mathrm{NaBH}_{4}$ (sodium borohydride, 98\%, Tianjin Fuchen Chemical Reagents Co.), $\mathrm{CO}\left(\mathrm{NH}_{2}\right)_{2}$ (urea, 99\%, Sigma-Aldrich), and KOH (Potassium hydroxide, 95\%, Tianjin Fuchen Chemical Reagents Corporation) were used.

\section{Synthesis of $\mathrm{Ni}(\mathrm{OH})_{2} / \mathrm{NF}$}

Firstly, Ni foam (NF, about $1 \times 1 \mathrm{~cm}^{2}$ ) is sonicated with $3 \mathrm{M}$ hydrochloric acid aqueous solution, ethanol, and deionized water for 15 minutes respectively to wash off oxides on the surface. Then, $5 \mathrm{mmol} \mathrm{Ni}\left(\mathrm{NO}_{3}\right)_{2} \cdot 6 \mathrm{H}_{2} \mathrm{O}$ and $10 \mathrm{mmol} \mathrm{HMT}$ are dissolved in $40 \mathrm{~mL}$ distilled water to form a uniform green solution under continuous stirring. The prepared solution and a piece of clean Ni foam are transferred to a $100 \mathrm{~mL}$ Teflon-lined stainless-steel autoclave, and then heated at $100{ }^{\circ} \mathrm{C}$ for $10 \mathrm{~h}$. After the reaction cools to $25^{\circ} \mathrm{C}$, the obtained $\mathrm{NF}$ with green $\mathrm{Ni}(\mathrm{OH})_{2}$ is washed with distilled water several times and dried at $60{ }^{\circ} \mathrm{C}$ in the oven.

\section{Synthesis of Ni-NiO/NF}

For the synthesis of the Ni-NiO compound on Ni foam, it is different from previous reports; the as-obtained $\mathrm{Ni}(\mathrm{OH})_{2} / \mathrm{NF}$ is directly calcined in $\mathrm{N}_{2}$ atmosphere at $300{ }^{\circ} \mathrm{C}$ for $2 \mathrm{~h}$ with $0.30 \mathrm{~g} \mathrm{NaBH}{ }_{4}$ at the upstream side of the porcelain boat. When the temperature is cooled down, the black film Ni-NiO/NF is finally obtained.

\section{Characterization}

Field emission scanning electron microscopy (FESEM, GeminiSEM 300) was used to obtain the morphology of the samples, and transmission electron microscopy (TEM, FEI Tecnai G2 F20) was used to confirm the microstructures of the catalysts. The crystal structures of the samples were measured using X-ray diffraction (XRD, D8-Advance; Bruker Miller), X-ray photoelectron spectroscopy (XPS, Axis Ultra; Kratos Analytical Ltd) was used to study the valence state of the elements, and Raman spectroscopy was recorded under the excitation of $532 \mathrm{~nm}$ laser light with a power of $20 \mathrm{~mW}$. The UV-Vis absorption spectra were collected at 200-800 nm against the $\mathrm{BaSO}_{4}$ reflectance standard. The realtime sample temperatures were measured using an IR thermograph (Ou PuShi PI450) during the experiment, and a $300 \mathrm{~W}$ Xe lamp (PLS-SXE 300C, Beijing Perfectlight Technology Co., Ltd, China) was used to simulate the full spectrum of solar light.

\section{Electrochemical measurements}

The electrochemical measurements are conducted using an electrochemical workstation (VMP3, SP-240, Bio-logic, France) in a threeelectrode system. The as-obtained samples on $\mathrm{Ni}$ foam were used as the working electrode, a graphite rod was used as the counter electrode and a $\mathrm{Hg} / \mathrm{HgO}(1 \mathrm{M} \mathrm{KOH})$ electrode was used as the reference electrode. The electrolyte was $1 \mathrm{M} \mathrm{KOH}$ with and without $0.33 \mathrm{M}$ urea aqueous solution. In all the measurements, the potentials used were converted into RHE, $E_{(\mathrm{RHE})}=E_{(\mathrm{Hg} / \mathrm{HgO})}+$ $0.059 \mathrm{pH}+0.098 \mathrm{~V}$. The catalytic performance of the three samples for the UOR and HER were evaluated by linear sweep voltammetry (LSV) at a scan rate of $10 \mathrm{mV} \mathrm{s}^{-1}$. Cyclic voltammetry (CV) is conducted with a scan rate of $50 \mathrm{mV} \mathrm{s}^{-1}$. Electrochemical impedance spectroscopy (EIS) was recorded in the frequency range from $100 \mathrm{kHz}$ to $0.1 \mathrm{~Hz}$ with a voltage amplitude of $-0.096 \mathrm{~V}$ in HER tests and $1.354 \mathrm{~V}$ in UOR tests. Chronoamperometry of UOR was tested in $1.354 \mathrm{~V} v$ s. RHE and HER was tested in $-0.106 \mathrm{~V} v s$. RHE. We sweep the potential between 0.6 to $0.8 \mathrm{~V} v s$. RHE at each of seven different scan rates $\left(20,40,60,80,100,120\right.$, and $\left.140 \mathrm{mV} \mathrm{s}^{-1}\right)$. By plotting the difference in current density $(j)$ between anodic and cathodic sweeps $\left(j_{\mathrm{a}}-j_{\mathrm{c}}\right)$ at a fixed potential against the scan rate, a linear trend is observed. The fitting slope is twice the double-layer capacitance $\left(C_{\mathrm{dl}}\right)$, which is linearly proportional to the ECSA. Urea electrolysis tests were measured in a two-electrode system with $\mathrm{Ni}-\mathrm{NiO} / \mathrm{NF}$ as the anode and cathode. The long-term durability of the Ni/NiO-NF electrode was assessed at constant voltage $(1.45 \mathrm{~V})$ electrolysis. All data for the two electrode tests were recorded without iR correction.

Light illumination is obtained by passing light from a $300 \mathrm{~W}$ Xenon lamp (PLS-SXE 300C, Beijing Perfectlight Technology Co., Ltd, China) and the power intensity of the incident light is calibrated to $150 \mathrm{~mW} \mathrm{~cm}{ }^{-2}$ at the surface of the working electrode. The light we used in the test of the photothermal part in this experiment is full spectrum light. The effect of irradiation wavelengths on the HER and UOR performance is investigated under various monochromatic lights which are obtained by using a series of band-pass filters $(350 \mathrm{~nm}, 400 \mathrm{~nm}, 450 \mathrm{~nm}, 500 \mathrm{~nm}, 550 \mathrm{~nm})$. The chronopotentiometric curve is measured at $-0.079 \mathrm{~V}$ versus RHE for the HER and $1.424 \mathrm{~V}$ versus RHE for the UOR to examine the electrochemical stability of Ni-NiO/NF without and with irradiation.

\section{Results and discussion}

The Ni-NiO/NF is synthesized through a hydrothermal route and the subsequent calcination reduction under the $\mathrm{N}_{2}$ atmosphere 
with $\mathrm{NaBH}_{4}$. The SEM images of precursor $\mathrm{Ni}(\mathrm{OH})_{2} / \mathrm{NF}$ are displayed in Fig. 1a. $\mathrm{Ni}(\mathrm{OH})_{2}$ nanosheets were grown on commercial Ni foam (SEM image of NF see Fig. S1, ESI $\dagger$ ), and the nanosheets were a few nanometers thick. As shown in Fig. 1b and $\mathrm{c}$, the SEM images of Ni/NiO-NF show that the nanosheet array remains unchanged but nanoparticle morphologies of the reduced Ni were observed. The TEM image (Fig. 1d) of Ni-NiO/NF also shows the two types of morphologies, in agreement with the SEM image results (Fig. 1c). The average diameter of the Ni nanoparticles of the sample was approximately $30 \mathrm{~nm}$, which forms heterojunctions with nanosheets. The HRTEM image (Fig. 1e) shows a lattice fringe of $0.202 \mathrm{~nm}$, corresponding to metal $\mathrm{Ni}$ (111) nanoparticles and a distance of $0.208 \mathrm{~nm}$ that can be indexed to the (200) plane of NiO. Fig. 1f exhibited two lattice fringe spacings of 0.238 and $0.173 \mathrm{~nm}$, which were assigned to the (111) of $\mathrm{NiO}$ and (200) of $\mathrm{Ni}$, respectively. The obtained HR-TEM images confirmed that the nanosheets were coexisting $\mathrm{NiO}$ and $\mathrm{Ni}$, and the formation of $\mathrm{Ni}$ nanoparticles was attributed to the $\mathrm{NaBH}_{4}$ reduction steps. The Raman spectra (Fig. 1g) show two peaks at about $520 \mathrm{~cm}^{-1}$ and $1090 \mathrm{~cm}^{-1}$ which are attributed to the vibration modes of $\mathrm{Ni}-\mathrm{O}$ bonds of NiO. The $\mathrm{X}$-ray diffraction (XRD) patterns (Fig. S2, ESI $\dagger$ ) indicate one weak diffraction peak at $43.3^{\circ}$ which is believed to be the (200) of NiO in $\mathrm{Ni}-\mathrm{NiO} / \mathrm{NF}^{29}$ The $\mathrm{NiO}$ phase with low crystallinity and the weak diffraction peak is caused by the strong peak signal of Ni. X-ray photoelectron spectroscopy (XPS) measurements of $\mathrm{Ni}(\mathrm{OH})_{2} /$ $\mathrm{NF}$ and $\mathrm{Ni}-\mathrm{NiO} / \mathrm{NF}$ were also conducted to study the chemical states of $\mathrm{Ni}$ and $\mathrm{O}$ species. As shown in Fig. $1 \mathrm{~h}$, for $\mathrm{Ni}(\mathrm{OH})_{2} / \mathrm{NF}$, the peaks centered at $855.1 \mathrm{eV}$ and $856.6 \mathrm{eV}$ can be assigned to $\mathrm{Ni}^{2+}$ and $\mathrm{Ni}^{3+}$, respectively. The peak is located at $861.2 \mathrm{eV}$ accompanied by the satellite peak. Compared with $\mathrm{Ni}(\mathrm{OH})_{2} / \mathrm{NF}$, a peak at $853.4 \mathrm{eV}$ appeared in the $\mathrm{Ni}-\mathrm{NiO} / \mathrm{NF}$, indicating the existence of metallic Ni species; in particular, the peaks of $\mathrm{Ni}^{2+}$ and $\mathrm{Ni}^{3+}$ shifted toward lower binding energy, implying that oxygen vacancies might be generated during the reduction process. $^{30,31}$ Similarly, as displayed in the $\mathrm{O}$ 1s spectrum (Fig. 1i), there are two peaks in $\mathrm{Ni}(\mathrm{OH})_{2} / \mathrm{NF}$ and three peaks in $\mathrm{Ni}-\mathrm{NiO} / \mathrm{NF}$. For $\mathrm{Ni}(\mathrm{OH})_{2} / \mathrm{NF}$, the peak at $530.9 \mathrm{eV}$ is assigned to $\mathrm{OH}^{-}$groups and the peak at $531.7 \mathrm{eV}$ is mainly assigned to the surface-adsorbed groups. For Ni-NiO/NF, the peak at $531.7 \mathrm{eV}$ can be attributed to the adsorbed oxygen species which is the same as $\mathrm{Ni}(\mathrm{OH})_{2} / \mathrm{NF}$ and another peak at $530.9 \mathrm{eV}$ is assigned to the oxygen vacancies. Additionally, the peak at $529.3 \mathrm{eV}$ corresponds to the lattice oxygen of NiO species. ${ }^{32,33}$ The full XPS spectrum of $\mathrm{Ni}-\mathrm{NiO} / \mathrm{NF}$ demonstrated the presence of $\mathrm{Ni}, \mathrm{O}$ and $\mathrm{C}$ species with $36 \%, 40 \%$ and $24 \%$ atomic concentration, respectively (Table S1, $\mathrm{ESI} \dagger$.

As a highly efficient photothermal material, the first requirement is a wide light adsorption capability. ${ }^{34}$ To determine the light absorption performances of the Ni-NiO/NF electrode, UV-vis absorption spectra of the $\mathrm{Ni}-\mathrm{NiO} / \mathrm{NF}$ and $\mathrm{NF}$ were measured. As displayed in Fig. 2a, both Ni-NiO/NF and NF exhibit absorption in ultraviolet, visible, and near-infrared regions. Compared with $\mathrm{NF}$, the Ni-NiO/NF composites showed more absorbance over the whole wavelength range, demonstrating that $\mathrm{Ni}-\mathrm{NiO} /$ NF exhibits a stronger near-infrared light absorption ability
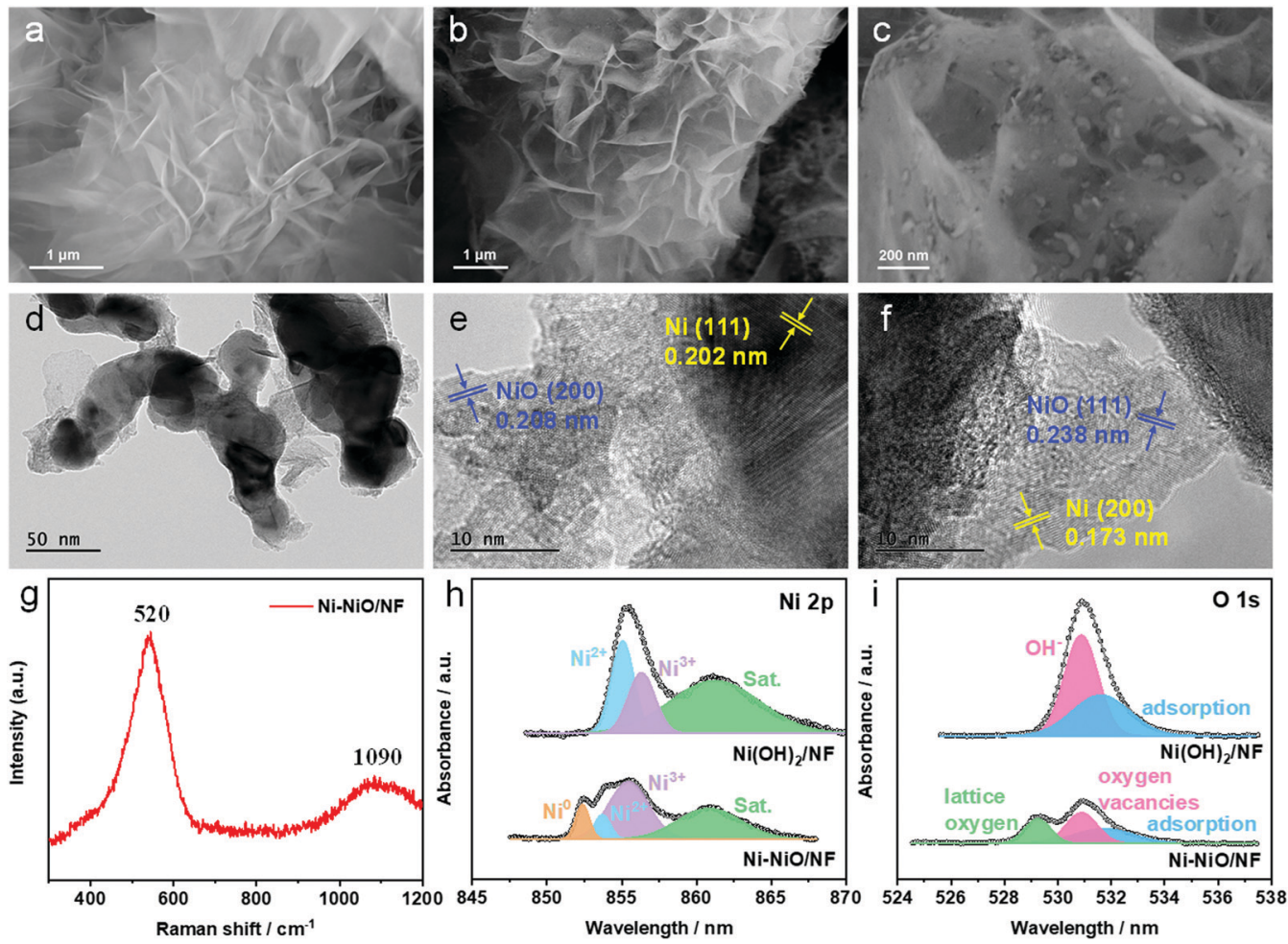

Fig. 1 (a) SEM image of the precursor $\mathrm{Ni}(\mathrm{OH})_{2} / \mathrm{NF}$. (b) Low-magnification SEM image, (c) high-magnification SEM image, (d) TEM image, and (e and f) HRTEM image of Ni-NiO/NF. (g) Raman spectrum of Ni-NiO/NF. XPS spectra of (h) Ni $2 p$ and (i) O $1 \mathrm{~s}$ in the sample of $\mathrm{Ni}-\mathrm{NiO} / \mathrm{NF}$. 
than NF. To investigate the photothermal effect of Ni-NiO/NF, the sample was placed in water under the illumination of a $300 \mathrm{~W}$ Xe lamp with the intensity of $150 \mathrm{~mW} \mathrm{~cm}^{-2}$ and the infrared camera was used to probe the surface temperature of the sample. As shown in Fig. 2b, the temperature of Ni-NiO/NF increases rapidly from $26.21{ }^{\circ} \mathrm{C}$ to $41.47^{\circ} \mathrm{C}$ (Fig. S3, ESI $\dagger$ ) within $60 \mathrm{~s}$ and was finally maintained at $48.98{ }^{\circ} \mathrm{C}$. The rapid temperature rises at the initial stage revealed that the sample has a high efficiency from light energy to thermal energy. Fig. 2c shows the time-dependent temperature curves of $\mathrm{Ni}-\mathrm{NiO} / \mathrm{NF}, \mathrm{Ni}(\mathrm{OH})_{2} / \mathrm{NF}$, and NF in the water with and without irradiation of light. All the samples were kept at the same initial temperature without irradiation, and then the temperature of the three samples increased rapidly under light irradiation. As the exposure time increases, the temperature rises slowly; when the irradiation of light was turned off, the temperature of all three materials dropped rapidly. It can be seen that $\mathrm{Ni}-\mathrm{NiO} / \mathrm{NF}$ exhibited the highest temperature of $36.69{ }^{\circ} \mathrm{C}$ which was higher than $\mathrm{Ni}(\mathrm{OH})_{2} /$ $\mathrm{NF}\left(34.52{ }^{\circ} \mathrm{C}\right)$ and $\mathrm{NF}\left(35.31{ }^{\circ} \mathrm{C}\right)$. The corresponding infrared images are shown in Fig. S4 (ESI $\dagger$ ). Therefore, the explanation might be that the Ni foam is a kind of material with a good photothermal effect, and when Ni-NiO nanosheets covered the Ni foam surface, due to their improved absorptance, the surface temperature was higher than using the Ni foam alone.

The UOR tests were carried out through a conventional three-electrode cell in $1 \mathrm{M} \mathrm{KOH}$ with $0.33 \mathrm{M}$ urea. Fig. 3a shows a comparison of the $\mathrm{CV}$ curves using $\mathrm{Ni}-\mathrm{NiO} / \mathrm{NF}$ catalysts in $1 \mathrm{M}$ $\mathrm{KOH}$ solution in the absence and presence of $0.33 \mathrm{M}$ urea. Compared with the $\mathrm{CV}$ curve in $1 \mathrm{M} \mathrm{KOH}$ solution, high current density was observed in the curve of the sample in $1 \mathrm{M} \mathrm{KOH}$ with $0.33 \mathrm{M}$ urea solution after $1.35 \mathrm{~V}$ vs. RHE, indicating high activity of the catalyst for urea oxidation. Linear sweep voltammetry (LSV) curves for the UOR and OER of the Ni-NiO/NF are shown in Fig. S5 (ESI $\dagger$ ). The peaks at about $1.37 \mathrm{~V}$ for the OER curves can be attributed to the redox pair of $\mathrm{Ni}^{2+} / \mathrm{Ni}^{3+} \cdot 35$ For comparison, the polarization curves of the $\mathrm{Ni}-\mathrm{NiO} / \mathrm{NF}, \mathrm{Ni}(\mathrm{OH})_{2} /$ $\mathrm{NF}$, and $\mathrm{NF}$ electrodes in $1.0 \mathrm{M} \mathrm{KOH}$ with $0.33 \mathrm{M}$ urea were displayed in Fig. 3b; in particular, the Ni-NiO/NF electrode demonstrated the best UOR performance among the samples. The onset potential is $1.35 \mathrm{~V}$, which is close to the potential at the beginning of the Ni redox, indicating that the newly formed NiOOH species is active for urea oxidation. ${ }^{36}$ Specifically, the current density of
$10 \mathrm{~mA} \mathrm{~cm}{ }^{-2}$ of Ni-NiO/NF requires only a small potential of $1.36 \mathrm{~V}$ vs. RHE, which is lower than that of $\mathrm{Ni}(\mathrm{OH})_{2} / \mathrm{NF}(1.37 \mathrm{~V})$ and the NF substrate $(1.39 \mathrm{~V})$. Notably, the polarization curves of the NF had an obvious oxidation peak at $\sim 1.56 \mathrm{~V} v$ s. RHE, which can be explained as the poor performance of NF for urea oxidation, and nickel foam has priority over its own oxidation of $\mathrm{Ni}^{2+}$ to $\mathrm{Ni}^{3+}$. The improved kinetics of the sample were also confirmed by the Tafel slopes (Fig. 3c). Ni-NiO/NF had the much lower Tafel slope of $32 \mathrm{mV} \mathrm{dec}^{-1}$, whereas $\mathrm{Ni}(\mathrm{OH})_{2} / \mathrm{NF}$ and $\mathrm{NF}$ had the values of 48 and $60 \mathrm{mV} \mathrm{dec}^{-1}$, respectively.

After exposure to the illumination by a $300 \mathrm{~W}$ Xenon lamp

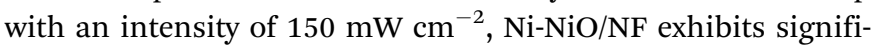
cantly enhanced UOR activities (Fig. 3d). The onset potential decreases from 1.35 to $1.33 \mathrm{~V}$, and the overpotential reduces to $1.34 \mathrm{~V}$ to achieve a current density of $10 \mathrm{~mA} \mathrm{~cm}{ }^{-2}$. When light irradiation was replaced by a water bath of $49{ }^{\circ} \mathrm{C}$, the overpotential was $1.36 \mathrm{~V}$ for a current density of $10 \mathrm{~mA} \mathrm{~cm}{ }^{-2}$, which is equal to that without illumination. For comparison, the UOR performance of nickel foam with and without light illumination was also tested (Fig. S6, ESI $\dagger$ ). The UOR activities of NF were almost the same before and after illumination. The results showed that the nickel foam could not improve the UOR activities under light conditions. The outstanding UOR catalytic behavior of Ni-NiO/NF under illumination is further evidenced by the Tafel plots shown in Fig. 3e. An obviously lower Tafel

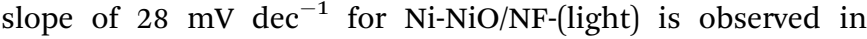
comparison to that in other conditions. Besides, electrochemical impedance spectroscopy (EIS) tests were also conducted to show solution resistance $\left(R_{\mathrm{S}}\right)$ and charge transfer resistance $\left(R_{\mathrm{ct}}\right)$ during urea oxidation (Fig. S7, ESI $\dagger$ ). This result shows that the Ni-NiO/NF electrode displays smaller $R_{\mathrm{ct}}$ and $R_{\mathrm{s}}$ under light illumination in contrast to that without light illumination. For a clear comparison, the voltages to reach current densities of 10 , 100,200 , and $300 \mathrm{~mA} \mathrm{~cm}^{-2}$ of $\mathrm{Ni}-\mathrm{NiO} / \mathrm{NF}$ in different conditions are listed in Fig. 3f. It can be seen that a water bath facilitates the reaction kinetics to enhance the electrocatalytic UOR performance. However, the UOR performance for the $\mathrm{Ni}-\mathrm{NiO} / \mathrm{NF}$ electrode enhanced significantly under illumination, which is superior to that in a water bath.

To further understand the enhanced electrocatalytic activities of Ni-NiO/NF under irradiation, intermittent irradiation was applied to the Ni-NiO/NF electrode (Fig. 3g). When the electrode
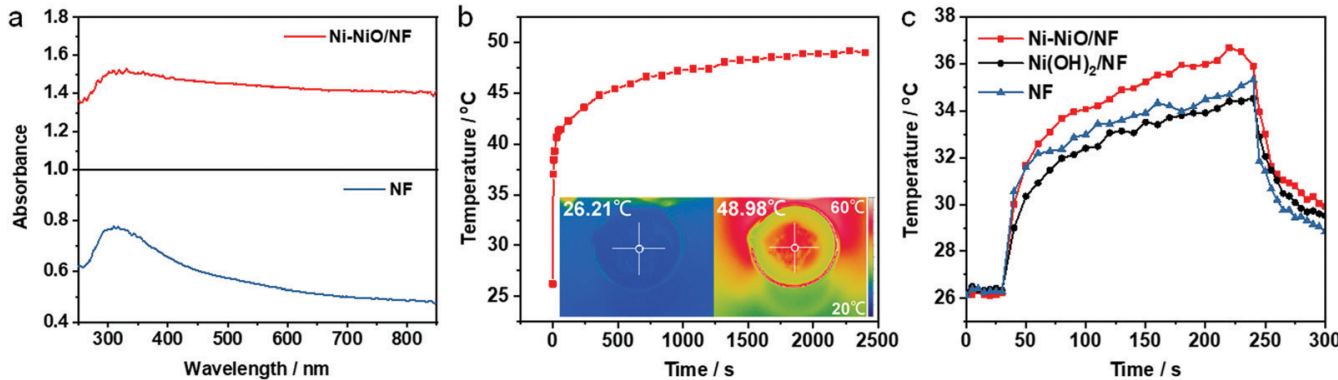

Fig. 2 (a) UV-vis absorbance spectra of $\mathrm{Ni}-\mathrm{NiO} / \mathrm{NF}$ and NF. (b) Time-dependent temperature curve of $\mathrm{Ni}-\mathrm{NiO} / \mathrm{NF}$ in the water under the irradiation of full spectrum light. Inset shows infrared thermal images of $\mathrm{Ni}-\mathrm{NiO} / \mathrm{NF}$ in the water before irradiation (left) and after irradiation (right) for $2400 \mathrm{~s}$. (c) Timedependent temperature curves of $\mathrm{Ni}-\mathrm{NiO} / \mathrm{NF}, \mathrm{Ni}(\mathrm{OH})_{2} / \mathrm{NF}$ and $\mathrm{NF}$ in the water with and without irradiation of light for $300 \mathrm{~s}$. 
a
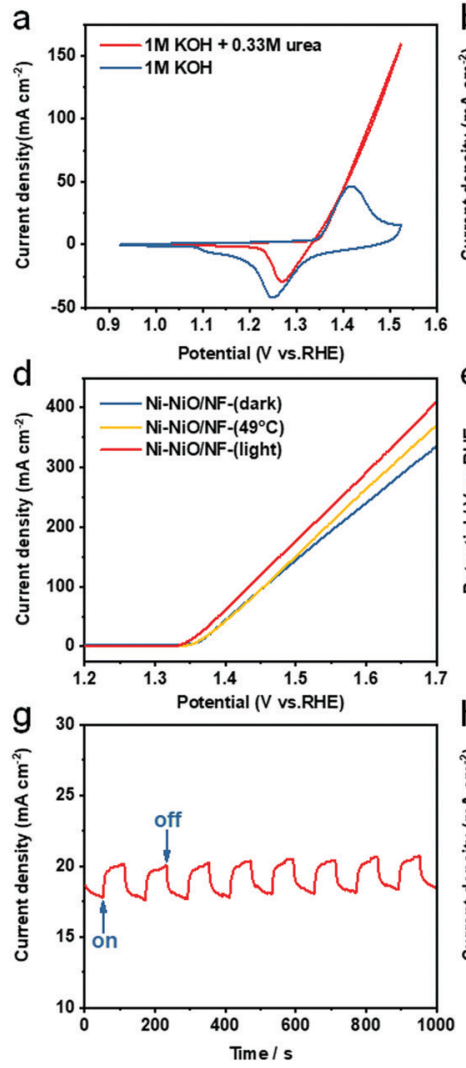
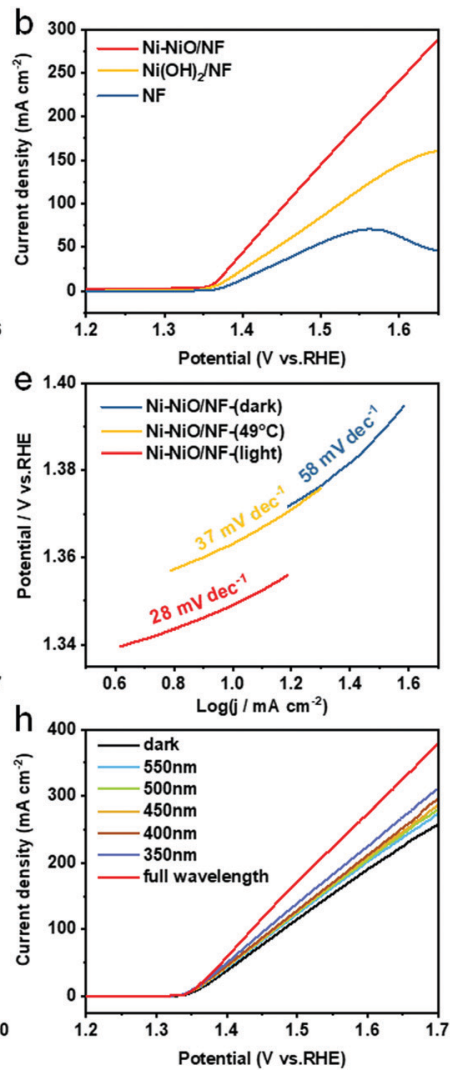
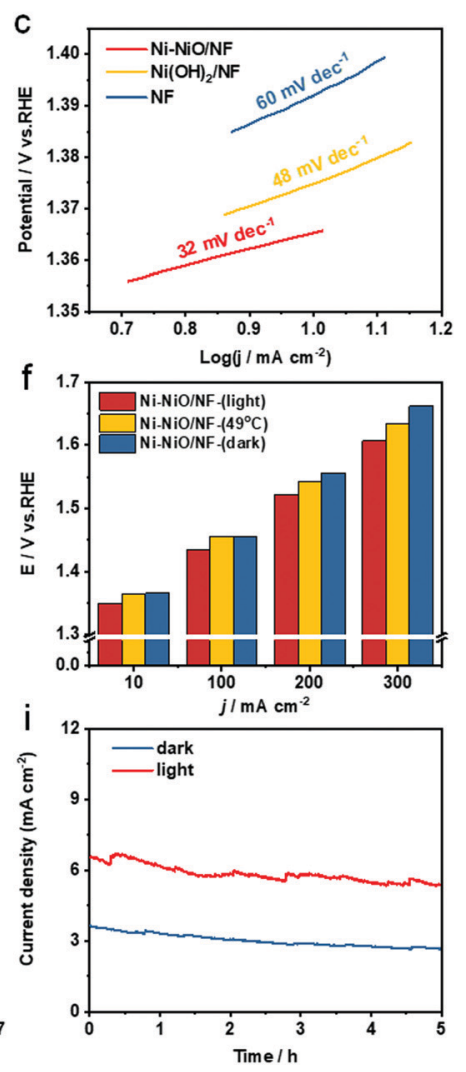

Fig. 3 (a) Cyclic voltammetry curves of $\mathrm{Ni}-\mathrm{NiO} / \mathrm{NF}$ in $1 \mathrm{M} \mathrm{KOH}$ and $1 \mathrm{M} \mathrm{KOH}$ with $0.33 \mathrm{M}$ urea. (b) Polarization curves of $\mathrm{Ni}-\mathrm{NiO} / \mathrm{NF}, \mathrm{Ni}(\mathrm{OH})_{2} / \mathrm{NF}$ and $\mathrm{NF}$ in $1 \mathrm{M} \mathrm{KOH}$ with $0.33 \mathrm{M}$ urea electrolyte at $10 \mathrm{mV} \mathrm{s}^{-1}$. (c) Tafel slopes of $\mathrm{Ni}-\mathrm{NiO} / \mathrm{NF}, \mathrm{Ni}(\mathrm{OH})_{2} / \mathrm{NF}$ and $\mathrm{NF}$ for the UOR. (d) UOR polarization curves of $\mathrm{Ni}-\mathrm{NiO} / \mathrm{NF}$ under the conditions of darkness, irradiation, and a water bath $\left(49^{\circ} \mathrm{C}\right)$ in $1 \mathrm{M} \mathrm{KOH}$ with $0.33 \mathrm{M}$ urea electrolyte. (e) Corresponding Tafel plots. (f) Voltage required to reach different current densities of the Ni-NiO/NF under different conditions. (g) Current density-time curve of the Ni-NiO/NF electrode during the UOR at a potential of $1.424 \mathrm{~V}$ vs. RHE under intermittent illumination. (h) UOR polarization curves of Ni-NiO/NF with different wavelengths of irradiation. (i) Time-dependent current density curves of Ni-NiO/NF without and with irradiation at $1.354 \mathrm{~V}$ vs. RHE for the UOR.

was under illumination, the current density obviously increased. When the illumination was turned off, the current density returned to the initial value rapidly. This result shows that the UOR performance can be enhanced on the Ni-NiO/NF electrode by photogenerated carriers from the excited NiO. ${ }^{37}$ The effect of irradiation wavelengths on UOR performance was displayed in Fig. 3 h. The UOR activity increased with a decrease in wavelength. As is well-known, photo-generated carriers are more easily excited at shorter wavelengths, while larger wavelengths can generate more thermal energy. Therefore, it indicates the effect of photogenerated carriers on UOR performance. Moreover, the band gap value of the p-type semiconductor $\mathrm{NiO}$ is $3.5 \mathrm{eV}$, but the performance is also improved with irradiation wavelength greater than $350 \mathrm{~nm}$, which may due to defects on the catalyst. Furthermore, the chronoamperometry test was conducted at a potential of $1.354 \mathrm{~V} v s$. RHE with and without irradiation. The steady current density of the Ni-NiO/NF catalyst may achieve $5.7 \mathrm{~mA} \mathrm{~cm}{ }^{-2}$ under irradiation, which is higher than that $\left(2.9 \mathrm{~mA} \mathrm{~cm}{ }^{-2}\right)$ without irradiation. This indicated that the Ni-NiO/NF electrode had good stability and the high durability of the irradiation-driven enhanced electrocatalytic activity (Fig. 3i).

The HER activity of Ni-NiO/NF was investigated in $1 \mathrm{M} \mathrm{KOH}$ with and without light irradiation. The polarization curves displayed that the HER activities of $\mathrm{Ni}-\mathrm{NiO} / \mathrm{NF}$ enhanced significantly after exposure to illumination. The overpotential decreases from 158 to $119 \mathrm{mV}$ at $10 \mathrm{~mA} \mathrm{~cm}^{-2}$ current density (Fig. 4a). The corresponding Tafel slopes obtained from the LSV curves are shown in Fig. $4 \mathrm{~b}$. The Tafel slope of the Ni-NiO/NF electrode with irradiation was $131 \mathrm{mV} \mathrm{dec}^{-1}$, which is superior to that of the $\mathrm{Ni}-\mathrm{NiO} / \mathrm{NF}$ electrode without irradiation $\left(151 \mathrm{mV} \mathrm{dec}^{-1}\right)$, indicating that the HER reaction kinetics of the Ni-NiO/NF electrode can be efficiently facilitated by light irradiation. The effect of irradiation monochromatic light with different wavelengths from $350 \mathrm{~nm}$ to $550 \mathrm{~nm}$ on HER performance was displayed in Fig. 4c. The HER performances were also performed in the same order with UOR: Ni-NiO/NF-(350 nm) $>$ Ni-NiO/NF$(400 \mathrm{~nm})>\mathrm{Ni}-\mathrm{NiO} / \mathrm{NF}-(450 \mathrm{~nm})>\mathrm{Ni}-\mathrm{NiO} / \mathrm{NF}-(500 \mathrm{~nm})>\mathrm{Ni}-\mathrm{NiO} /$ $\mathrm{NF}-(550 \mathrm{~nm})$. In addition, Ni-NiO/NF exhibits a rapid reproducible current response to the light on and off cycles at the HER typical potential (Fig. 4d). These results also demonstrate that the photogenerated carriers via photo-excited semiconductors enhanced the electrocatalytic performance. In order to investigate the photothermal effect on the electron transfer ability of the Ni$\mathrm{NiO} / \mathrm{NF}$ electrode, electrochemical impedance spectroscopy (EIS) measurements were further conducted, as shown in Fig. 4e. The EIS result has shown that the catalyst with light illumination 

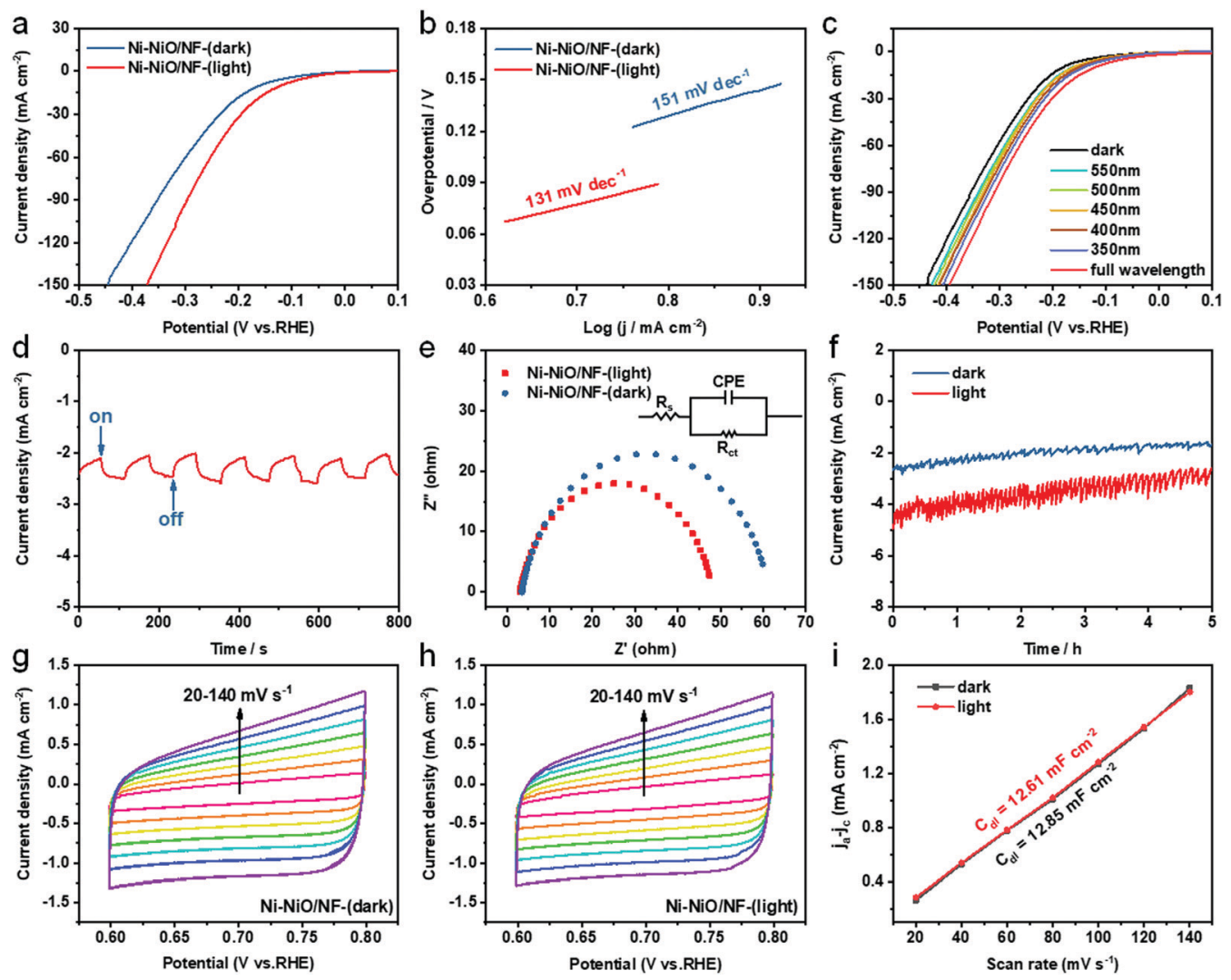

Fig. 4 (a) HER polarization curves of $\mathrm{Ni}-\mathrm{NiO} / \mathrm{NF}$ under the conditions of darkness and irradiation in $1 \mathrm{M} \mathrm{KOH}$ electrolyte at $10 \mathrm{mV} \mathrm{s}{ }^{-1}$. (b) Corresponding Tafel plots. (c) HER polarization curves of $\mathrm{Ni}-\mathrm{NiO} / \mathrm{NF}$ with different wavelengths of irradiation. (d) Current density-time curve of the $\mathrm{Ni}-\mathrm{NiO} / \mathrm{NF}$ electrode during the HER at a potential of $-0.079 \mathrm{~V}$ vs. RHE under intermittent illumination. (e) Nyquist plots of Ni-NiO/NF at $-0.096 \mathrm{~V} v$ s. RHE. (f) Time-dependent current density curves of Ni-NiO/NF without and with irradiation at $-0.106 \mathrm{~V} v$ s. RHE for the HER. ( $\mathrm{g}$ and $\mathrm{h}$ ) CV curves for Ni-NiO/NF between $0.6 \mathrm{~V}$ and $0.8 \mathrm{~V}$ vs. RHE in $1 \mathrm{M} \mathrm{KOH}$ at various scan rates. (i) Plots showing the extraction of double-layer capacitance of $C_{\mathrm{dl}}$ for $\mathrm{Ni}-\mathrm{NiO} / \mathrm{NF}$ under the conditions of darkness and irradiation.

possesses a much smaller charge transfer resistance $\left(R_{\mathrm{ct}}\right)$ in contrast to that without light illumination, indicating faster electron transport. Furthermore, the stabilities of HER with light illumination exhibit higher current density over time than that without light illumination (Fig. 4f). The periodic fluctuation may be due to the accumulation and removal of generated $\mathrm{H}_{2}$ bubbles on the electrode surface.

Moreover, to further ascertain the effect of illumination on the active sites, the electrochemical active surface areas (ECSAs) of the Ni-NiO/NF electrode with and without light illumination were estimated by extracting the electrochemical double-layer capacitance $\left(C_{\mathrm{dl}}\right)$ from the $\mathrm{CV}$ measurements (Fig. $4 \mathrm{~g}$ and $\mathrm{h}$ ). And the capacitance is usually considered to be proportional to the electrochemical active area. ${ }^{38}$ It is found that the $C_{\mathrm{dl}}$ of $\mathrm{Ni}-\mathrm{NiO} / \mathrm{NF}$ under illumination $\left(12.61 \mathrm{mF} \mathrm{cm}^{-2}\right)$ is close to that without illumination $\left(12.85 \mathrm{mF} \mathrm{cm} \mathrm{cm}^{-2}\right)$ (Fig. 4i). Hence, the improved performance of $\mathrm{Ni}-\mathrm{NiO} / \mathrm{NF}$ in the UOR and HER with illumination cannot be explained by the improved active surface area and increased active sites. As a result, the significantly improved activity should be mainly ascribed to the increased electronic density and the optimized reaction kinetics.

Inspired by the remarkable catalytic abilities of the $\mathrm{Ni}-\mathrm{NiO} /$ NF electrode for the UOR and HER, a two-electrode electrolyzer was constructed to estimate the performance of electrochemical hydrogen generation with the $\mathrm{Ni}-\mathrm{NiO} / \mathrm{NF}$ electrode as both the anode and cathode (Fig. 5a). As shown in Fig. 5b, the cell voltage needed by the $\mathrm{Ni}-\mathrm{NiO} / \mathrm{NF}|| \mathrm{Ni}-\mathrm{NiO} / \mathrm{NF}$ in the electrolyzer in $1 \mathrm{M}$ $\mathrm{KOH}+0.33 \mathrm{M}$ Urea with illumination to achieve the current density at $10 \mathrm{~mA} \mathrm{~cm}^{-2}$ is $1.48 \mathrm{~V}$, which is lower than that without illumination $(1.54 \mathrm{~V})$, clearly showing the superior cell efficiency of urea oxidation assisted $\mathrm{H}_{2}$ production under illumination. It can be concluded that the assistance of urea oxidation can lower the energy consumption of hydrogen production. Moreover, the $\mathrm{Ni}-\mathrm{NiO} / \mathrm{NF}$ electrode demonstrated excellent performance in urea-assisted electrochemical hydrogen production when compared with other reported materials (Table S2, ESI $\dagger$ ). Furthermore, the stability of the Ni-NiO/NF||Ni-NiO/NF in the HER-UOR electrolyser was tested at $1.45 \mathrm{~V}$ in $1 \mathrm{M} \mathrm{KOH}+0.33 \mathrm{M}$ urea with and without irradiation for $5 \mathrm{~h}$ (Fig. 5c). The current density decreased in the first hour and then achieved equilibrium and remained constant during $4 \mathrm{~h}$. Moreover, the current density under irradiation is $4 \mathrm{~mA} \mathrm{~cm}{ }^{-2}$, which is 2-fold higher than that without irradiation $\left(2 \mathrm{~mA} \mathrm{~cm}^{-2}\right)$, suggesting the good stability of the irradiation-driven enhanced urea electrolysis. The morphology and surface chemical states of the $\mathrm{Ni}-\mathrm{NiO} / \mathrm{NF}$ catalyst were further probed by the SEM, TEM, XRD and XPS techniques after the 
a

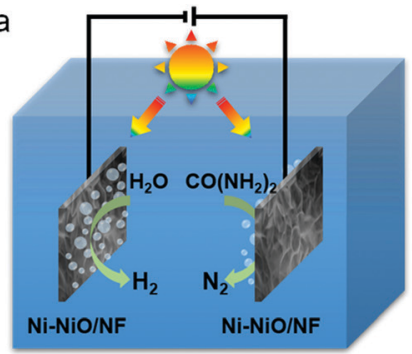

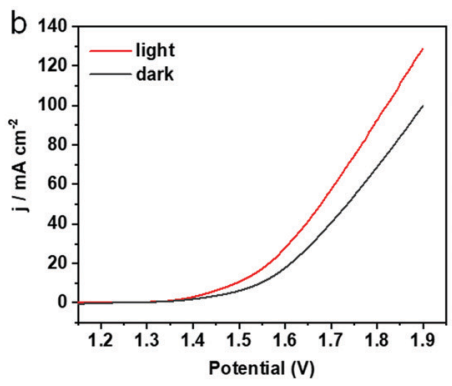

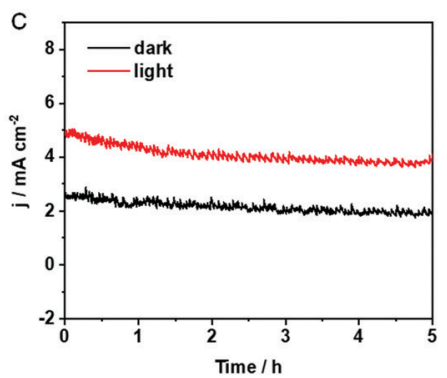

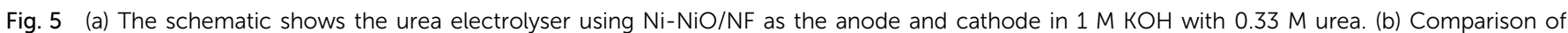

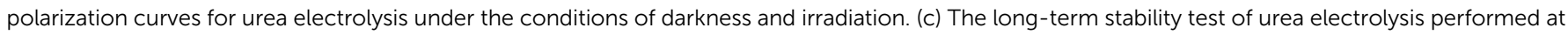
a cell voltage of $1.45 \mathrm{~V}$.

durability test (Fig. S8, ESI $\dagger$ ). The nanosheet array morphology of $\mathrm{Ni}-\mathrm{NiO} / \mathrm{NF}$ was still maintained, as confirmed by the SEM and TEM images (Fig. S8a and 8b, ESI $\dagger$ ). The fringes assigned to the (111) plane of $\mathrm{Ni}$ and the (200) plane for NiO were still discovered, and a new fringe of $0.241 \mathrm{~nm}$ assigned to the interplanar spacing of the (002) plane of $\beta-\mathrm{NiOOH}$ was found, suggesting the formation of high valence Ni species during the electrochemical catalytic process (Fig. S8c, ESI $\dagger$ ). The XRD patterns still indicate one weak diffraction peak at 43.30 which is believed to be the (200) of NiO (Fig. S8d, ESI $\dagger$ ). According to the XPS Ni 2p spectrum given in Fig. S8e (ESI $\dagger$ ), the peak of $\mathrm{Ni}^{3+}$ is larger than that before the reaction, indicating high valence Ni species of $\beta-\mathrm{NiOOH}$. Fig. S8f (ESI $\dagger$ ) shows that the oxygen adsorption on the surface increases. The surface oxidation and $\mathrm{Ni}^{3+}$ increase due to the catalyst surface was significant for the high catalytic ability and durability of the $\mathrm{Ni}-\mathrm{NiO} / \mathrm{NF}$ catalyst in urea-assisted water electrolysis.

\section{Conclusions}

In summary, the Ni-NiO/NF electrodes exhibit exceptional catalytic performance for the UOR and HER by the photo-driven effect strategy. This hybrid catalyst could be synthesized through a facile hydrothermal method and subsequent calcination reduction processes. Under illumination, the overpotential of the UOR decreases from $1.36 \mathrm{~V}$ to $1.34 \mathrm{~V}$ at $10 \mathrm{~mA} \mathrm{~cm}{ }^{-2}$ and it decreases $39 \mathrm{mV}$ at $10 \mathrm{~mA} \mathrm{~cm}^{-2}$ for the HER. Furthermore, a two-electrode electrolyser composed of Ni-NiO/NF electrodes as both the anode and cathode requires a small voltage of $1.48 \mathrm{~V}$ under illumination to attain 10 $\mathrm{mA} \mathrm{cm}{ }^{-2}$, indicating the excellent urea-assisted water electrolysis activity. It is found that the greatly enhanced HER \& UOR activities can be ascribed to the efficient light absorption and subsequent conversion to thermally accelerated $\mathrm{Ni}-\mathrm{NiO} / \mathrm{NF}$ reaction kinetics. Another reason is that the photogenerated electron transfer of the excited NiO can enrich electronic density, thereby improving the activity. This work may open new approaches to fabricate highefficiency bifunctional electrocatalysts for urea oxidation assisted $\mathrm{H}_{2}$ production by using the renewable power of solar energy.

\section{Author contributions}

Qi Wang: Conceptualization, Methodology, Investigation, Writingoriginal draft; Xing Cheng: Formal analysis, Data curation; Yukun
Sun: Validation, Data curation; Zaicheng Sun: Data curation; Dong Wang: Writing-review \& editing; Ge Chen: Writing-review \& editing, Supervision; Peter Schaaf: Writing-review \& editing.

\section{Conflicts of interest}

There are no conflicts to declare.

\section{Acknowledgements}

This work was supported by the National Science Foundation of China (NSFC 12075015), and the Beijing Municipal High Level Innovative Team Building Program (No. IDHT20180504).

\section{Notes and references}

1 Y. Li, H. Wang, C. Priest, S. Li, P. Xu and G. Wu, Adv. Mater., 2020, 2000381.

2 M. Wu, J. Liao, L. Yu, R. Lv, P. Li, W. Sun, R. Tan, X. Duan, L. Zhang, F. Li, J. Kim, K. H. Shin, H. Seok Park, W. Zhang, Z. Guo, H. Wang, Y. Tang, G. Gorgolis, C. Galiotis and J. Ma, Chem. - Asian J., 2020, 15, 995-1013.

3 L. Ye and Z. Wen, Chem. Commun., 2018, 54, 6388-6391.

4 Y. Feng, C. Xu, E. Hu, B. Xia, J. Ning, C. Zheng, Y. Zhong, Z. Zhang and Y. Hu, J. Mater. Chem. A, 2018, 6, 14103-14111.

5 L. C. Seitz, C. F. Dickens, K. Nishio, Y. Hikita, J. Montoya, A. Doyle, C. Kirk, A. Vojvodic, H. Y. Hwang, J. K. Norskov and T. F. Jaramillo, Science, 2016, 353, 1011.

6 X. Gao, H. Zhang, Q. Li, X. Yu, Z. Hong, X. Zhang, C. Liang and Z. Lin, Angew. Chem., Int. Ed., 2016, 55, 6290-6294.

7 T. Take, K. Tsurutani and M. Umeda, J. Power Sources, 2007, 164, 9-16.

8 Y. X. Chen, A. Lavacchi, H. A. Miller, M. Bevilacqua, J. Filippi, M. Innocenti, A. Marchionni, W. Oberhauser, L. Wang and F. Vizza, Nat. Commun., 2014, 5, 4036.

9 C. Huang, Y. Huang, C. Liu, Y. Yu and B. Zhang, Angew. Chem., Int. Ed., 2019, 58, 12014-12017.

10 Y. Wang, Y. Yu, R. Jia, C. Zhang and B. Zhang, Natl. Sci. Rev., 2019, 6, 730-738.

11 G. Wang and Z. Wen, Nanoscale, 2018, 10, 21087-21095.

12 N. Chen, Y.-X. Du, G. Zhang, W.-T. Lu and F.-F. Cao, Nano Energy, 2021, 81, 105605. 
13 Z.-Y. Yu, C.-C. Lang, M.-R. Gao, Y. Chen, Q.-Q. Fu, Y. Duan and S.-H. Yu, Energy Environ. Sci., 2018, 11, 1890-1897.

14 B. K. Boggs, R. L. King and G. G. Botte, Chem. Commun., 2009, 4859-4861.

15 Y. Liang, Q. Liu, A. M. Asiri and X. Sun, Electrochim. Acta, 2015, 153, 456-460.

16 D. Zhu, C. Guo, J. Liu, L. Wang, Y. Du and S.-Z. Qiao, Chem. Commun., 2017, 53, 10906-10909.

17 Y. Ding, Y. Li, Y. Xue, B. Miao, S. Li, Y. Jiang, X. Liu and Y. Chen, Nanoscale, 2019, 11, 1058-1064.

18 D. Liu, T. Liu, L. Zhang, F. Qu, G. Du, A. M. Asiri and X. Sun, J. Mater. Chem. A, 2017, 5, 3208-3213.

19 X. Zhu, X. Dou, J. Dai, X. An, Y. Guo, L. Zhang, S. Tao, J. Zhao, W. Chu, X. C. Zeng, C. Wu and Y. Xie, Angew. Chem., Int. Ed., 2016, 55, 12465-12469.

20 R. Ding, L. Qi, M. Jia and H. Wang, Nanoscale, 2014, 6, 1369-1376.

21 Y. Shi, J. Wang, C. Wang, T.-T. Zhai, W.-J. Bao, J.-J. Xu, X.-H. Xia and H.-Y. Chen, J. Am. Chem. Soc., 2015, 137, 7365-7370.

22 G. Liu, P. Li, G. Zhao, X. Wang, J. Kong, H. Liu, H. Zhang, K. Chang, X. Meng, T. Kako and J. Ye, J. Am. Chem. Soc., 2016, 138, 9128-9136.

23 S.-S. Wang, W.-C. Hu, F.-F. Liu, Q.-Y. Xu and C. Wang, Electrochim. Acta, 2019, 301, 359-365.

24 X. Han, Y. Yu, Y. Huang, D. Liu and B. Zhang, ACS Catal., 2017, 7, 6464-6470.

25 J. Wang, L. Zhu, G. Dharan and G. W. Ho, J. Mater. Chem. A, 2017, 5, 16580-16584.
26 L. Zhu, M. Gao, C. K. N. Peh and G. W. Ho, Mater. Horiz., 2018, 5, 323-343.

27 B. Jin, Y. Li, J. Wang, F. Meng, S. Cao, B. He, S. Jia, Y. Wang, Z. Li and X. Liu, Small, 2019, 15, 1903847.

28 L. Zhu, M. Gao, C. K. N. Peh, X. Wang and G. W. Ho, Adv. Energy Mater., 2018, 8, 1702149.

29 N. Liu, J. Li, W. Ma, W. Liu, Y. Shi, J. Tao, X. Zhang, J. Su, L. Li and Y. Gao, ACS Appl. Mater. Interfaces, 2014, 6, 13627-13634.

30 Y. Pan, G. Hu, J. Lu, L. Xiao and L. Zhuang, J. Energy Chem., 2019, 29, 111-115.

31 W. Zhou, X.-F. Lu, J.-J. Chen, T. Zhou, P.-Q. Liao, M. Wu and G.-R. Li, ACS Appl. Mater. Interfaces, 2018, 10, 38906-38914.

32 Q. Xu, G. Qian, S. Yin, C. Yu, W. Chen, T. Yu, L. Luo, Y. Xia and P. Tsiakaras, ACS Sustainable Chem. Eng., 2020, 8, 7174-7181.

33 Y. Wang, F. Cao, W. Lin, F. Zhao, J. Zhou, S. Li and G. Qin, J. Mater. Chem. A, 2019, 7, 17834-17841.

34 D.-D. Wu, D. Qu, W.-S. Jiang, G. Chen, L. An, C.-Q. Zhuang and Z.-C. Sun, J. Mater. Chem. A, 2019, 7, 8485-8490.

35 H. Liu, Z. Liu and L. Feng, Nanoscale, 2019, 11, 16017-16025.

36 G. Das, R. M. Tesfaye, Y. Won and H. H. Yoon, Electrochim. Acta, 2017, 237, 171-176.

37 Z. Sun, Y. Liang, Y. Wu, Y. Yu and B. Zhang, ACS Sustainable Chem. Eng., 2018, 6, 11206-11210.

38 Q. Wang, H. Wang, X. Cheng, M. Fritz, D. Wang, H. Li, A. Bund, G. Chen and P. Schaaf, Mater. Today Energy, 2020, 17, 100490. 